\title{
Translation Axiology and Erratology: Cultural Information and Symmetry
}

\author{
Veronica A. Razumovskaya* \\ Siberian Federal University \\ 79 Svobodny, Krasnoyarsk, 660041, Russia
}

Received 17.01.2016, received in revised form 07.02.2016, accepted 24.02.2016

The article deals with the range of axiological and erratological problems in the area of literary translation. A special attention is given to the notion "translation quality" and the nature of a translation error and irregularity considered through the terms of generally scientific categories of symmetry and harmony. The quality of a "strong" literary text translation is directly connected with the elimination of cultural errors caused by a number of subjective and objective reasons.

Keywords: translation quality, symmetry, asymmetry, harmony, disharmony, cultural information, translation error, translation irregularity.

DOI: 10.17516/1997-1370-2016-9-3-579-587.

Research area: philology.

\section{Introduction}

At different stages of the centuries-long history of translation studies the problem of quality always intrigued theorists and experts, as well as critics and, of course, readers. In no way undermining the importance of the quality in all types of translation and interpretation, it is worth emphasizing that the quality of literary translation has a particular significance explained by at least two reasons, i.e. by a relatively long "life" (preservation) of a printed text and, consequently, by availability of its printed translation for most readers. The importance of axiological range of problems is proved by permanent searches and implementation of various criteria for the translation quality evaluation during different historical periods and within many national translation traditions. Undoubtedly, the criteria of quality taken in temporal and space perspectives, have a high degree of variability according to a positivistic principle ad hoc: every single translation is made only in a certain place, time and situation of contacting languages.

\section{The Notion of Quality and the Corresponding Scientific Categories}

At the present time the notional framework of translation studies includes a number of regular axiological notions and scientific categories, by the terms of which the translation quality can be described. Such categories include symmetry, harmony, isomorphism and isomerism. All of them have a universal and general scientific

(C) Siberian Federal University. All rights reserved

* Corresponding author E-mail address: veronica_raz@hotmail.com 
character that corresponds with a contemporary tendency towards the scientific unification. We can't but agree with the fact that "axiological translation" which, indeed, strongly needs to be created and developed, may have axiological linguistics, that meets today the requirements of anthropocentric approach in translation, as one of its probable "prototype" (Ivanova et al. 2015). Thus, axiological translation is conformable with the desire for understanding of aspects and problems of axiological linguistic analysis, as well as proper methodology and methods (Serebrennikova 2008).

The perspectives for further successful development of "axiological translation" are closely connected with the implementation of an adequate axiological translation analysis that is also needed to be worked out.

A sound and multivarious axiological experience gained due to different types of translation and different pairs of translation languages, can present a stable ground for the creation of "axiological translation", that absolutely corresponds to anthropocentric approach so much used in many human sciences. Without any doubt, there is a reasonable necessity in practicalimplementation of the abovementioned hypothesis.

By the nature of the case, many specialists turned to the notion of "good translation" at all stages in its centuries-long history: from the ancient theorists and critics (Saint Jerome, E. Dolet), theorists and practitioners during the Renaissance era (L. Bruni) and the Reformation (M. Luther) to scientific ideas of the $20^{\text {th }}$ century (G. Eger, A.D. Shweitser, V.N. Komissarov). Criteria for the translation quality were most typically defined on the basis of two categories, dominating for a long time within the categorical paradigm of the contemporary translation studies, i.e. equivalence and adequacy. The same approach to the definition of the quality has been presented in the one of the latest axiological theories of translation in Russia (Sdobnikov, 2015).

In the present time, those translation ideas characterized by an obvious axiological focus, are the frontier. Thus, concerning axiological aspects of translation under the idea of translation space as a synergetic model of translation, researches from the Russian city Perm have recognized the harmony as a new axiological dominant category of translation. In this case, one may talk of possible creation of a certain translation quality evaluation system, introducing opposite categories such as harmony (qualitative translation) and disharmony (translation failure). The central place in this system would be taken by such traditional translation categories as adequacy and equivalence (Kushninova, Alikina 2010; Nazmutdinova, 2008). Presenting the highest degree of the quality in translation, the harmony finds its expression through the category of relevance. "...in the case of clash or miss of relevancies, the disharmony is in evidence; in the case of relevancies engagement within two languages in contact, a translator can reach the proper level of adequacy and equivalence; the highest stage of the translation quality is represented by the harmony resulted by interaction of the relevancies in languages and cultures within their contact" (Nazmutdinova 2008: 7). Recognizing a certain metaphoricity of the harmony as a notion in the current scientific discourse, the abovementioned Russian researchers claim, that according to their currently developed idea of the translation space, the harmony is considered to be a sustainable criterion for the translation quality analysis.

Apart from the category of relevance, the axiological category of harmony is closely connected with the scientifically universal category of symmetry, presenting the basis for the principle of regular structure, i.e. the symmetry law. It is the symmetry that presents one of the most important element of the 
harmony. Being a basic element of the harmony, the symmetry is an essential part in the history of arts and creative activity of a person within the art and, most importantly, in science (Caglioti 1998). The notion of symmetry is a hot issue for literary translation as a meeting point of the art and science. One of the essential conditions for the equivalence between two objects or phenomena is the existence of the symmetry relation between them. The symmetry is usually defined as a feature of binary relations (regardless the nature of objects and phenomena connected by these relations) and acts as the universal and "permanent" category in both science and arts. Similar to equivalence, the symmetry can be explained through the general scientific notions of compliance, similarity, analogy and identity.

The literary translation is traditionally considered to be a sophisticated and unique combination of the science and arts which can not be completely separated within the subject matter of translation. To be more precise, the process of literary translation corresponds to a complex creative activity, peculiar both to the science and arts. According to the abovementioned statement, the literary translation can figuratively be defined through a neo-term "science-art", allowing to describe this type of translation as some sort of a hybrid science or, vice versa, a hybrid art. The proportion and form of the ratio between the components of science and arts vary in each specific case of translation, equivalent to the principle ad hoc described above. Obviously, the ratio of scientific and art characteristics cannot be initially set by the translator: it is formed just within the translation depending on the language and cultural features of the source text, as well as on the similarities and differences between languages and cultures involved. The pointed evident hybrid nature of the literary translation gives us an opportunity to concern the theoretical and practical issues of this translation with the assistance of a number of universal scientific and artistic categories, providing an efficient and complementary approach to the current topical problems concerned in the context of this sort of communication.

Thus, as a universal category, the symmetry is also a fundamental and general principle for the whole macrocosm, i.e. both for the animate and inanimate nature and the society itself. The symmetry does not simply surround a person. The symmetry is a universal basis of the nature in which a human plays an essential part (Urmantsev, 1974). Reasoning and realizing of its universalism can be seen through the whole history of the world civilization. It has undergone certain changes: from the perception as a specific notion in geometry to the recognition of its scientific universalism, that builds the ground for many fundamental laws of the nature and creation. "The symmetry is the notion which characterizes the process of self-transition under certain transformations; widely, it is an invariant character of certain sides, processes and relations between the objects in their reference to some transformations $<\ldots>$ In philosophic sense, the symmetry is described as a specific type of the structural organization of objects (Filosofskii entsiklopedicheskii slovar 1983: 608). This definition shows the most important ideas of the symmetry, making it a central agent in the analysis of problems on translation in general, as well as on the literary translation and its quality in particular. These important methodological notions include "shift", "transformation" and "invariance". Within the translation any original text undergoes different qualitative and quantitative transformations and, as the result, is transformed into the secondary text which preserves, however, the initial invariant part (to various extent in each case of translation). A 
certain degree of invariance in the original and translated texts does exactly guarantee the quality of translation.

The other traditional basic element of the harmony is asymmetry, i.e. an antipode of the symmetry. The combination of symmetry, asymmetry and the result of their interaction that is, harmony - provides us with valuable aesthetic features of phenomena that has these parameters in different degrees and combinations. The notion of symmetry allows identifying and describing the order, proportion, quiescence, balance and sustainability belonging to the object or phenomenon. Being opposite to the notion of symmetry, the asymmetry marks disorder, misbalance and changes in the object or phenomenon. These two categories taken within the space of a certain object or phenomenon of art, represent an inseparable dialectical unity, and their relations and contact contribute to the general dialectical unity and struggle of opposites. Being completely opposite to each other, the symmetry and asymmetry form a continued categorical unity.

Thus, considering the harmony as one of the key axiological categories of aesthetic objects, including literary texts, it becomes quite reasonable to use the notions of harmony and disharmony, symmetry and asymmetry in order to appraise the quality of literary translation.

The analysis of axiological problems of the literary translation is directly connected with the whole range of translation failures, composing a separate branch of the translation studies called translation erratology. As in the case of axiology, which uses the experience of many neighboring humanities, the translation erratology is based on the linguistic material. Numerous examples of translation failures and their analysis are shown particularly in linguistic studies. This fact suggests building a separate scientific field in linguistics, i.e. erratology with its own subject, object and methodology. As the theory of errors, erratology concerns the problematics within linguistic and many other humane disciplines through a new perspective. This idea was comprehensively considered in numerous researches by famous Russian and foreign theorists of translation (N.K. Grabovskii, V.N. Komissarov, A.D. Shweitzer, B. MoserMercer).

The analysis of the translation challenges nature and, as a consequence, errors, has a great importance for the quality achievement and rests on the data from different field of experience. Thus, in the linguistic translation studies a special role was usually assigned to comparative linguistics that differentiates all the language levels, and also to quite a new branch called confrontive linguistics, concerning both differences and similarities of the language systems. Viewing through the results of translation, the erratology is introduced in the modern scientific discourse as the theory of translation errors (Shevnin 2005). One of the most crucial tasks for the translation erratology is the development of the translation errors taxonomy (Buzadzhi, Gusev, Lanchikov, Psurtsev 2009; Maksiutina 2010).

\section{Translation Errors and Translation Irregularities}

It is worth mentioning that there is no common definition for the notion of translation error, and even no clear difference between a translation error and translation irregularity. In the same way, the problem of the translation errors classification is still under the discussion. The development of this classification and creation of a sustainable scale for the translation evaluation are certainly a demanding task for modern analysts, since there are both the complexity and ambiguity of the evaluated object and an obvious subjectivity in understanding the nature of such errors. One must admit that detailed 
and scientifically proved taxonomies of the translation errors has been introduced recently. Thus, L.K. Latishev and A.L. Semionov have suggested distinguishing between errors within the translation of the original content and errors coming from the adaptation of the content and form of the target text (Latishev, Semionov 2003: 164-171). The first group, in its turn, can also be subdivided into three folds: misrepresentations, irregularities and ambiguities. The taxonomy of the translation errors pioneered by N.K. Grabovskii is based on the reasons why they occur (poor command of the source language; lack of extra linguistic knowledge on the source text environment; misunderstanding of the source meaning and features of the author's individual style). Within this classification, semantic errors are quite frequently concerned as a type of the translation errors, and since so they further can be subdivided in different ways depending on the degree of understanding (Garbovskii 2004: 514-536). Another interesting treatment of this axiological issue has been described in the work by S.V. Tiulenev, putting forward the idea that the translation quality should be evaluated according to the mediation function that provided the target readers with an opportunity to get to know the source text (Tiulenev 2004). A new take on the translation quality problems has been promoted by a group of authors who has fully considered these problems and the question of classification of errors regarded as all sorts of defects in translation (Buzadji, Gusev, Lanchikov, Psurtsev 2009). Under this conception the notion of error is considered together with the translation categories of equivalence and adequacy, providing a possibility to identify the "seriousness" of errors and range them into four basic groups. Besides, the first group includes two categories: (1) denotatively misrepresenting errors (nonmotivated omissions, adding or replacements impeding the equivalence and adequacy) and (2) denotatively non-misrepresenting errors (changes in pragmastylistical dominants of the source text, the word order in the translation, alogism). Errors relating to the first category are considered by the authors as the most "serious". The second group includes those errors belonged to the violation of the functional, style and genre features of the source text; the third group is composed of the errors based on troubles within connotative and expressive potentials of the source text; the fourth one contains errors coming from the breaking of norms and usage, spelling and punctuation. It must be mentioned, that all the above mentioned types of classification do not include a precise differentiation between translation errors and translation irregularities. Let's emphasize that the notion of translation irregularities is included into the idea of a translation error according to the hypo-hyperonimic principle. A commonplace for the considered taxonomies is laying the focus on semantic errors and recognizing them as the most crucial for the translation quality.

By accepting the necessity of distinguishing between the translation error and irregularity, one can hypothetically suppose that a possible basis for differentiating an error from irregularity in translation may well be analyzed above the category of harmony/disharmony and symmetry/ asymmetry. To be more precise, translation errors are made within the violation of symmetry and appearance of disharmony between the source and target texts.

The description of the degree of agreement between two texts, taken in the context of the universal scientific category of symmetry, suggests that in the case of a translation success the target text would be a symmetrical reflection (or a comparatively symmetric reflection) of the source text. Since in translation we particularly deal with the language objects, so the definition for the translation quality in this sense is related to identification of the language symmetry 
appearances which can be found on the basis of symmetric elements affiliation to a certain language level. Through that hierarchic approach, a phonetic, morphologic, syntactic and lexical (the most vivid one) symmetries are usually established. In this case, the greatest significance is possessed by the symmetry of formal and content parameters of the primary and secondary texts. Within the field of the translation studies such types of symmetry as graphic, aesthetic, conceptual and cultural are less well understood. There are no completely symmetrical or asymmetrical source or target texts, that is explained by the objective asymmetry of the language and culture systems involved into the process of translation. The ratio and proportion of symmetrical and asymmetrical elements and structures in the source and target texts result in a definite translation quality. Considering the symmetry and asymmetry as extreme points in the whole conceptual space of symmetry, it becomes necessary to mention, that there are at least two evident symmetrical phenomena, i.e. anti-symmetry and dissymmetry. The first one involves preservation of some characteristic of the object and substitution of the other for an opposite one. In this sense, asymmetry should be distinguished from dissymmetry understood as a decrease in the symmetry, or an absence of its certain elements. Dissymmetry means a partial absence of symmetry, or its disorder expressed in the presence of only some symmetrical features (Ponomarenko 2007; Sonin 1987). Speaking about the symmetry, in most cases the researchers de facto deal with the appearance of dissymmetry, since "a pure symmetry" is limited and, as a rule, finds its expression in a static form, widely occurring in classical crystallography. Thus, the asymmetry and disharmony in the translation are resulted in an error. The translation irregularities correlate with the anti-symmetry and dissymmetry.

\section{Cultural Translation Errors and Irregularities}

Within the area of literary translation, it is vitally important to take into account the phenomenon of cultural symmetry. The cultural symmetry/asymmetry of the source and target texts are reasonably determined by the similarities and differences between cultures involved into the process of translation. A source literary text a priori contains a cultural information (cultural experience, national and cultural semantics), i.e. the information about main events, persons, traditions, beliefs, ordinary realia related to the life of a certain culture. The cultural information features some internal ("inside") and external ("outside") types and focuses on the material (goods and things) and spiritual (norms, values, rituals, symbols, myths, customs and traditions) cultures. In the scientific discourse, maintenance of a certain (or the most important) part of the cultural information is defined as a cultural memory. This phenomenon involves one of external measures for the human memory and appears to be an imprecise and quite frequently modified information about past events. Still, in comparison with the cultural information characterized by a relatively precise nature and unavailability for all member of the society, the cultural memory is a common and uniting property of the nation. The cultural memory means the cultural information which has undergone the process of understanding and acceptance by the mass consciousness.

While dealing with any literary text, a translator faces two main obstacles related to the preservation (reconstitution) of the source cultural information in translation: (1) to identify the language units possessing this cultural information and memory; (2) to reconstruct this information in the target text. Thus, the cultural translation errors are caused by two main reasons. The first reason is due to 
wrong perception and decoding of the cultural information implied in the source literary text, that can be caused by a low competence level and not sufficient translation training, lack of knowledge on the extralinguistic environment, as well as by inexperience and inattentiveness of a translator. Those translation errors connected with failures in reconstruction of the source cultural information in the target text, may well be driven by the objective asymmetry of the language and cultural systems involved into translation, along with wrong decisions for the translation. The cultural translation errors can be classified as semantic translation errors. A wrong or incomplete transferring of the cultural information misrepresents the original intention implied in the source literary text, significantly reduces aesthetic potential of the target text and desired impact on a reader. The translation irregularity, in its turn, decreases the aesthetic power of the secondary text in the same way, but it does not crucially affect on the information perception. The ability to overcome probable translation errors and cultural irregularities has a particular importance within the translation of "strong" text. This type of texts are put into the situation of a permanent informational resonance both with other "strong" texts of the "inside" and "outside" cultures and with its readers. "Strong" literary texts are considered exactly to be a "storage" and "generator" of the cultural information, as well as the most popular and regular objects for the literary translation. This fact requires from the translator to perform their work as accurately as possible.

\section{Conclusions}

Despite the current attention towards the problems of the translation quality in general, and particularly, of the literal translation quality, the translation studies has not got yet any commonly accepted and fixed set of criteria allowing an objective evaluation of the translation results. The problem of determining the translation quality includes two aspects, i.e. axiological and erratological ones, dialectically interconnected and based on the universal scientific categories. The translation quality, varying within the coordinates "low - high" and the nature of translation errors and irregularities can be defined and described through the terms of symmetry/ asymmetry and harmony/disharmony.

\section{References}

Buzadzhi, D.M., Gusev, V.V., Lanchikov, V.K., Psurtsev, D.V. (2009). Novii vzgliad na klassifikatsiiu perevodcheskih oshibok [A new insight in the classification of translation errors]. Moscow, Vserossiiskii centr perevodov, $118 \mathrm{p}$.

Caglioti, G. (1998). Ot vospriiatiia k mysli. O dinamike neodnoznachnogo i narusheniiah simmetrii $v$ nauke $i$ iskusstve [The dynamics of ambiguity and broken symmetry in science and art]. Moscow, Mir, $221 \mathrm{p}$.

Filosofskii entsiklopedicheskii slovar [Encyclopedia of philosophy]. Moscow, Sovetskaia enciklopediia, 1983, $840 \mathrm{p}$.

Garbovskii, N.K. (2004). Teoriia perevoda [Theory of translation]. Moscow, Izdatelstvo Moskovskogo universiteta, $544 \mathrm{p}$.

Ivanova, O.A. Krivoruchko, A.I., Pogorelaia, N.G. (2015). Aksiologicheskaia paradigma perevoda: $k$ voprosu o subjektivnyh i objektivnyh kriteriiah otsenki kachestva perevoda [Axiological paradigm of translation: on the problem of objective and subjective criteria for the translation quality evaluation], In Sovremennie problemi nauki i obrazovaniia [Topical problems of science and education]. 1 (1).

$$
-585-
$$


Kushninova, L.V., Alikina, E.V. (2010). Garmoniya v sisteme otsenki kachestva ustnogo perevoda [Harmony in the system of the interpretation quality evaluation], In Vestnik Tyumenskogo gosudarstvennogo universiteta [Bulletin of the State University of Tyumen] 1, 141-147.

Latishev, L.K., Semenov, A.L. (2003). Perevod: teoriia, praktika i metodika prepodavaniia [Translation: theory, practice and teaching methodology]. Moscow, Akademiya, $192 \mathrm{p}$.

Maksiutina, O.V. (2010). Perevodcheskaia oshibka v metodike obucheniia [Translation error within the teaching methodology], In Vestnik Tomskogo gosudarstvennogo pedagogicheskogo universiteta [Bulletin of Tomsk State Pedagogical University] 1(91), 49-52.

Nazmutdinova, S.S. (2008). Garmoniya kak perevodcheskaya kategoriia (na materiale russkogo, angliiskogo, frantsuzskogo kinodiskursa): avtoref. dis. ... kand. filol. nauk [Harmony as a translation category (a case study of Russian, English and French film discourse: extended abstract of Cand. Sci. (Philology) thesis]. Tyumen, $21 \mathrm{p}$.

Ponomarenko, I.N. (2007). Lingvisticheskaia aspektizatsiia universalnogo printsipa simmetrii [Linguistic aspectizing of the universal principle of symmetry], In Uchenie zapiski Tavricheskogo natsionalnogo universiteta im. V.I. Vernadskogo. Seriia «Filologiia» [Proceedings of Tavrida National V.I. Vernadkii University, Philology] 3 (20), 283-287.

Sdobnikov, V.V. (2015). Otsenka kachestva perevoda: kommunikativno-funktsionalnyi podhod [Translation quality evaluation: communicational and functional approach]. Moscow, FLINTA, $112 \mathrm{p}$.

Serebrennikova, E.F. (2011). Aspekti aksiologicheskogo lingvisticheskogo analiza [Aspects of axiological linguistic analysis], In Lingvistika i aksiologiia: etnosemiotriia tsennostnih smislov [Linguistics and axiology: ethnosemiotry of axiological values]. Moscow, TEZAURUS, 7-26.

Shevnin, A.B. (2005). Erratologiia: teoriia oshibok i perevodcheskih nesootvetstvii [Erratology: the theory of errors and translation irregularities]. In Vestnik Yuzhno-Uralskogo gosudarstvennogo universiteta. Seriia: Lingvistika [Bulletin of South Ural State University, Linguistics] 11 (51), 111113.

Sonin, A.S. (1987). Postizhenie sovershenstva: simmetriia, asimmetriia, dissimetriia, antisimmetriia [Discovering the perfection: symmetry, asymmetry, dissymmetry, anti-symmetry]. Moscow, Znanie, 208 p.

Tiulenev, S.V. (2004). Teoriia perevoda [Theory of translation]. Moscow, Gardariki, $336 \mathrm{p}$.

Urmantsev, Iu.A. (1974). Simmetriia prirody i priroda simmetrii [Symmetry in the nature and the nature of symmetry]. Moscow, Mysl, 229 p. 


\section{Аксиология и эрратология перевода: \\ культурная информация и симметрия}

В.А. Разумовская

Сибирский федеральный университет Россия, 660041, Красноярск, пр. Свободный, 79

В статье рассматриваются аксиологическая и эрратологическая проблематика художественного перевода. Особое внимание уделяется определению понятия «качество перевода» $и$ природы переводческой ошибки и переводческого несоответствия в терминах общенаучных категорий симметрии и гармонии. Качество перевода «сильного» художественного текста напрямую связано с преодолением ошибок культурного типа, появление которых обусловлено рядом субъективных и объективных причин.

Ключевые слова: качество перевода, симметрия, асимметрия, гармония, дисгармония, культурная информация, переводческая оиибка, переводческое несоответствие.

Научная специальность: 10.00.00 - филологические науки. 